\title{
EVIDÊNCIAS NOS ESTUDOS DAS FINANÇAS COMPORTAMENTAIS E INFLUÊNCIAS NAS TOMADAS DE DECISÕES
}

EVIDENCE IN BEHAVIORAL FINANCE STUDIES AND INFLUENCES IN DECISION$M A K I N G$

\author{
LIMA, Glaucia Fátima ${ }^{1}$; FELIPE, Fábio Isaias ${ }^{2}$ \\ ${ }^{1}$ Discente do MBA em Finanças e Controladoria, Fundação Hermínio Ometto - Uniararas \\ ${ }^{2}$ Docente, Fundação Hermínio Ometto, Uniararas \\ glaucia limaf@yahoo.com.br
}

\begin{abstract}
RESUMO. Esse artigo tem como objetivo abordar a evolução dos estudos na área de finanças comportamentais, considerando os efeitos sobre a tomada de decisões dos indivíduos. Utilizouse da revisão bibliográfica como método de pesquisa, considerando os avanços na área, a qual revela que, simples emoções esclarecem as anomalias de mercados pelas quais entram em contradição com o princípio do mercado eficiente e, os resultados inferem que, o planejamento financeiro com finanças comportamentais envolve equilíbrio ao indivíduo, pois são fatores relevantes que visam efeitos qualitativos ao mesmo no qual é demonstrado insights que contribuem para a melhor decisão a ser tomada e a necessidade de um método pelo qual revisa a maneira cujas decisões são tomadas bem como a busca por aconselhamento em determinadas escolhas vindas por indivíduos auxiliares que estão fora do contexto da tomada de decisão, focando no planejamento em que realizar hoje e em suas possíveis falhas a um futuro próximo junto ao levantamento de questões referentes aos riscos de perdas.
\end{abstract}

Palavras-chave: finanças comportamentais, tomadas de decisões, indivíduos.

ABSTRACT. This article aims to address the evolution of studies in the area of behavioral finance, considering the effects on the decision making of individuals. We used the bibliography review as a research method, considering the advances in the area, which reveals that, simple emotions clarify the market anomalies by which they contradict the efficient market principle, and the results infer that financial planning with behavioral finances involves balance to the individual, once they are relevant factors that aim qualitative effects to the same one in which insights are shown to contribute to the best decision to be made and the requirement of a method by which it assess the way decisions are made as well as the search for advice on certain choices made by supporting individuals who are outside the context of decision making, focusing on the current planning and on its possible shortcomings in the near future, conciliated with questions regarding the risks of losses.

Key words: behavioral finance, decision making, individuals.

\section{INTRODUÇÃO}

Novos desafios e tendências à gestão de riscos vêm tomando conta do dia a dia dos indivíduos, dentre estes há o seu comportamento que, interfere diretamente nas tomadas de decisões pelas quais podem vir a resultar de forma positiva ou negativa em seu futuro, uma vez que, decisões são tomadas baseadas em suas emoções, intuições, diversificando assim de forma inadequada suas carteiras (KAHNEMAN, 2015). 
A busca por produtos e/ou serviços no mercado globalizado leva os indivíduos agirem compulsivamente sem pensar em suas políticas direcionadas ao seu capital, uma vez que, são estas que tornam relevante o mercado financeiro o qual reflete diretamente no desenvolvimento, crescimento e sobrevivência de seu meio.

A confiança excessiva faz com que investidores reverenciem determinadas aptidões de que podem dominar o mercado. Para Hersh Shefrin (2000 apud LIMA, 2003) junto aos pesquisadores deste conceituado tema, "Phil Cooley foi um dos primeiros pesquisadores a aplicar as descobertas dos psicólogos e estudar as atitudes de risco de administradores de portfólio, publicando seu trabalho em 1977 no 'Journal of Finance"'.

A necessidade de análise ao impacto causado pelas tomadas de decisões visa à influência direta na bolsa de valores cujo resultado é relativo ao comportamento dos agentes financeiros que tem influência diferenciada neste mercado.

As finanças comportamentais para Donadio (2018), “[...] tentam entender como as pessoas tomam decisões financeiras, tanto individual quanto coletivamente.", ou seja, a autora relata que, através deste estudo é possível obter o conhecimento sobre fatores relevantes que interferem nas tomadas de decisões influenciando assim em seus resultados.

Os investidores, peça chave da economia, tem uma visão relevante nas tomadas de decisões, suas habilidades com o mercado financeiro interferem nos resultados que conquistam este mercado, porém pesquisadores apontam que, a realidade não chega a ser desta forma, uma vez que, segundo Odean, (1998 apud LIMA, 2003, p. 8) há evidência em que:

Analisando mais de 10 mil negócios de investimento no mercado financeiro norteamericano, concluiu que os papéis vendidos tiveram um desempenho $3,4 \%$ maior do que os papéis comprados nessas negociações. ODEAN, (1998 apud LIMA, 2003, p. 8)

Os tomadores de recursos e investidores concedem a negociação de produtos financeiros, como títulos públicos, ações, fundos de investimentos, entre outros, o que gera recursos que visibilizam a possibilidade de investimentos geradores de lucros bem como, com riscos de perdas.

Os analistas financeiros são indicados em um processo prolongado quando se trata de inspecionar suas pré-avaliações de comportamentos vindouros de uma determinada organização, sendo assim, é possível observar que, a autoconfiança não chega a ser escassa a um investidor peculiar.

Este trabalho busca evidenciar as tomadas de decisões baseadas no comportamento dos indivíduos bem como suas emoções pelas quais visam interferir diretamente nos resultados de forma que, o indivíduo fique satisfeito ou não com os resultados uma vez que, o processo de tomada de decisão requer cuidados com os meios pelos quais influenciam no objetivo que se espera alcançar.

\section{METODOLOGIA}

A metodologia utilizada neste trabalho é a revisão de literatura, a qual apresenta as características relevantes ao tema. Para Gil, (2002), há diferentes entendimentos para a composição de uma pesquisa, tendo dois grupos relevantes pelos quais podem ser classificadas, sendo razões de ordem intelectual e razões de ordem prática, sendo a primeira pelo anseio em se notar pelo próprio desejo em fazê-la e a segunda trabalhando-se a maneira pela qual viabilizam procedimento sendo este eficiente ou eficaz.

A pesquisa do material utilizado foi feita a partir de referenciais teóricos de diferentes 
autores que abordam o tema sobre finanças comportamentais, onde foi possível observar a escassez de dados referente a este tema conceituado e importante para as tomadas de decisões, que podem interferir diretamente nos resultados promovendo ganhos ou perdas.

Para Martins e Theóphilo, (2009), em pesquisas qualitativas, as grandes massas de dados são quebradas em unidades menores e, em seguida, reagrupadas em categorias que se relacionam entre si, de forma ressaltar padrões, temas e conceitos. A pesquisa qualitativa envolve o estimulo, ambição, e procedimentos relacionados a processos pelos quais visam a busca por informações intensas com qualidades diferenciadas que permitirão um processo eficaz na decorrência do mesmo.

Contudo, Gonsalves (2007) apresentou uma classificação de pesquisa, conforme os tópicos a seguir:

- Tipos de pesquisa segundo seus objetivos - Exploratória, Descritiva, Experimental e Explicativa;

- Tipos de pesquisa segundo os procedimentos - Experimento, Levantamento, Estudo de caso, Bibliográfica, Documental e Participativa;

- Tipos de pesquisa segundo as fontes de informação - Campo, Laboratório, Bibliográfica e Documental;

- Tipos de pesquisa segundo a natureza dos dados - Quantitativa e Qualitativa.

As etapas seguidas neste trabalho foram fundamentais para o desenvolvimento do processo de levantamento de dados, seleção das informações adequadas e ainda, a veracidade das informações pelas quais o tornou relevante para a conclusão do mesmo com os termos abordados no decorrer desta pesquisa.

\section{RESULTADOS E DISCUSSÃO}

\section{Teorias Comportamentais em Finanças}

De acordo com Kahneman (2015), o planejamento financeiro juntamente às finanças comportamentais permite que, o indivíduo faça parte de situações que causem menos riscos de perdas levando-o aos caminhos que visam abordar a construção de seus recursos de forma quantitativa e qualitativa visando ainda o cumprimento de seus objetivos. A necessidade de equilíbrio entre finanças comportamentais e planejamento é relevante para que se cumpra os fatores pelos quais contribuirão para a eficiência nas tomadas de decisões.

Milanez (2003) afirma que a teoria de finanças comportamentais conhecida também por economia comportamental, envolve a busca da absorção dos mercados financeiros no qual o seu desempenho é relevante para o ciclo de vida econômico possibilitando assim o apoio cuja função contribuirá para apresentar ao desenho da política econômica. $\mathrm{O}$ autor apresenta nesta teoria que, os fatores psicológicos interferem na avaliação e identificação nos ativos financeiros feita pelos indivíduos.

Donadio (2018) destaca que a tradicional Teoria de Finanças e a Teoria Econômica Clássica, consideram que os indivíduos têm conhecimento limitado de alternativas para a tomada de decisões e capacidade cognitiva também limitada para a escolha de uma melhor combinação de resultados, quando se trata de investimentos.

A necessidade humana causa determinado impacto em suas ações seguindo ao tocante de melhorias em seu bem-estar por satisfazer seus desejos e, para Kahneman, as decisões tomadas precisam ser registradas de tal forma que sejam relevantes para um futuro próximo. Ainda para Kahneman (2015), 


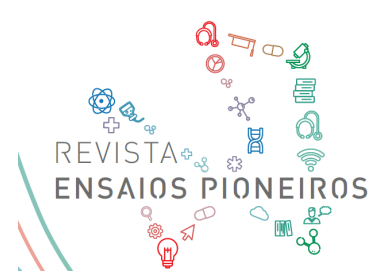

Quando um plano estratégico estiver sendo formulado, o gestor deve convocar os envolvidos para uma reunião, na qual será apresentado o seguinte cenário: estamos um ano no futuro, implementamos o plano e o resultado foi um desastre. Cada participante deve usar uma folha de papel para escrever a história do fracasso. Em seguida, o gestor deve recolher as anotações e lê-las em voz alta. A ideia é legitimar o dissenso. KAHNEMAN, (2015, p. 51).

Kahneman, (2015) ressalta a necessidade de pensar nos riscos futuros bem como, suas possíveis falhas, ou seja, precaver o que pode acontecer como se já estivesse a um ano desse planejamento e, assim, preestabelecer ações pelas quais poderão interferir no processo para que se obtenha um resultado eficaz aprendendo assim, com seus possíveis erros e se possível validar os desacordos que podem ocorrer. Este mesmo autor relata ainda que, há desigualdade entre decisões adequadas e resultados adequados pelos quais o indivíduo procura analisar a decisão independente de qual resultado for obtido, ou seja, nem sempre as decisões tomadas podem atingir o resultado que se espera obter.

É inevitável a necessidade de analisar as expectativas que se tem interesse para as causas que podem ocorrer nas tomadas de decisões, pois estas influenciam diretamente nos resultados cuja consequência é pertinente ao comportamento dos agentes financeiros que possuem influência diferenciada no mercado em questão.

\section{Tomadas de Decisões}

Sbicca (2004), considera que a distorção de preços bem como dos rendimentos, demonstra a anomalia de mercado, ou seja, o desiquilíbrio, um possível erro, no qual pode ser assimilado como a natureza pela qual se explica através de uma organização teórica na qual se faz parte de um elemento-chave utilizando-se de heurístico pelo qual se compreende por si mesmo.

O mercado é visto como uma rede de relações entre os indivíduos no qual acontece o contato social, pesquisas apontam que, o mercado é executado por um grupo onde se distribui em grupos pesquisados referindo-se aos sardinhas como sendo os compradores de pequeno porte, e por outro lado o grupo de outros denominado de tubarões que representam os investidores em maior parte os quais se diferem. (TOMASELLI; OLTRAMARI, 2007).

Estudos têm refletido sobre situações diversas pelas quais se referem dos agentes de mercado, cujo comportamento se difere da racionalidade com a teoria neoclássica onde relatam que, os investidores, sendo estes os elementos mais importantes do mercado financeiro, fortalecem informações de empresas pelas quais obtiveram andamento eficaz no passado deixando de apresentar os riscos ocorridos, provocando assim, lacunas com falhas nas informações. Ainda neste contexto há investidores que não aceitam perdas, nesta circunstância, é possível observar que, este comportamento evidencia a interferência das condições psicológicas nas tomadas de decisões. MILANEZ (2003).

No fator psicológico, o investidor não tem o mesmo valor entre perdas e ganhos, ou seja, na perda o psicológico tem um peso maior, o que o leva a melhoria de sua capacidade em tomar decisões o que pode evitar as possíveis falhas em decisões futuras.

Contudo, a tomada de decisão adequada é relevante para a obtenção de ganhos adequados conforme o tipo de investimento, a falha em uma tomada de decisão levará o investidor a sérios riscos de perdas. No entanto, é importante atentar-se a necessidade de controlar as decisões através da construção do conhecimento na busca de fatores pelos quais contribuem para o alcance do objetivo esperado com troca de informações junto aos investidores que já conhecem o ramo de atuação que, assim poderá contribuir para um resultado 


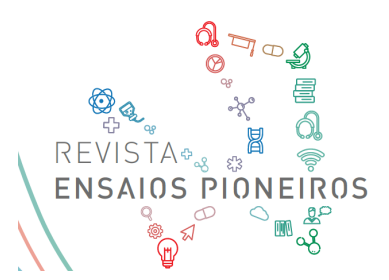

eficaz.

\section{Comportamentos de Investidores}

A economia influencia diretamente no mercado de ações sendo neste aspecto acompanhada pelos membros que operam os mercados de capitais. A informação sobre a alta e baixa deste mercado é espontânea devido aos variados meios de comunicação que permitem aos interessados desta área acompanharem todo o processo. É fato que, o indivíduo é visto de maneira diferente pela Psicologia como caráter subjetivo no qual possui uma opinião pessoal em determinada situação e, para a Economia é visto como caráter racional onde se é feito uma análise da situação antes da tomada de qualquer decisão. ALMEIDA (2017).

Mesmo que, uma determinada ação esteja em alta hoje, os ruídos (noise ${ }^{1}$ ) de que se faz diferença na compra da mesma é relevante, pois os investidores fazem com que se desconheça um passado promissor no qual ocorreram possíveis perdas que podem influenciar em um futuro próximo. A aversão à perdas e intervenção social pode interferir no indivíduo o levando a um comportamento pelo qual afeta os demais envolvidos. ALMEIDA (2017).

Ponpian (2012a, apud ALMEIDA, 2017, p. 42) cita alguns diferentes modelos de comportamentos de investidores, sendo eles:

- Preservador - aversão à perdas, ancoragem e status quo;

- Seguidor - framing (enquadramento), caráter de recência, viés de retrospectiva;

- Independente - reação exagerada (overreaction), viés de confirmação, viés de disponibilidade;

- Acumulador - sobre confiança, ilusão de controle.

A necessidade de equilíbrio entre a Psicologia Econômica bem como o Planejamento Financeiro é relevante para riscos menores, pois o envolvimento em um investimento cujo objetivo é o aumento de recursos, a necessidade de agir com a razão é considerável, uma vez que, ao permitir que emoções e excesso de autoconfiança interfiram sem ao menos uma pesquisa de mercado bem como sua investigação, poderá afetar na demanda de lucros ou perdas significativas. O indivíduo é movido pela sua emoção, porém em determinadas situações é indispensável uma segunda opinião antes da tomada de qualquer decisão pela qual envolve seus recursos. KAHNEMAN (2015).

Através da pesquisa realizada, foi possível observar entre os autores trabalhados que, estudos apontam o conhecimento de investidores sem experiência, pelos quais na tomada de decisão para investir na bolsa de valores à considera como um mercado de risco e especulativo e, outros indicam ser uma oportunidade melhor de rentabilidade e, que quando esta sofre uma queda, a decisão seria em manter a carteira por um determinado período. Tais pensamentos refletem a realidade pela qual mesmo sem experiência, há um determinado conhecimento que, aprimorado pode se obter um resultado eficaz. ALMEIDA (2017).

$\mathrm{O}$ desconhecimento sobre investimentos gera insegurança e, até mesmo graves riscos de perdas em determinadas decisões, no entanto, a necessidade de análise do ambiente e a busca por conhecimentos na área pela qual se pretende investir.

\section{Considerações finais}

É notório que, os investidores buscam pelo ganho do desiquilíbrio diário pelo qual ocorre

\footnotetext{
1 "O conceito de ruído é aplicado ao mercado de ações quando se refere ao tipo de investidor que realiza várias operações em um mesmo dia." ALMEIDA (2017).
} 


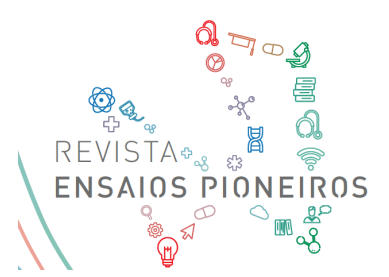

no mercado financeiro e, que o excesso de confiança gera possíveis falhas em um futuro próximo. A necessidade de pesquisar, planejar e buscar informações relevantes interferem nos investimentos como forma de melhoria no processo, uma vez que, citando o mercado de ações como exemplo, o que está em alta hoje, não possui garantia de que se obterá lucros, pois há um histórico que precisa ser investigado e levantar os pontos que identificam se obterá lucro ou se é garantido correr riscos neste investimento. ALMEIDA (2017).

O processo de identificar falhas e riscos no processo de investimento é considerável eficaz antes da tomada de decisão, bem como planejar, analisar o cenário, buscar um histórico de experiências já ocorridas por outros indivíduos até mesmo das empresas pelas quais se pretende investir. KAHNEMAN (2015).

O comportamento interfere nas ações do indivíduo, pois suas emoções variam fazendo com que tome a decisão correta ou não e, é indispensável que, se obtenham opiniões de terceiros, também a busca por informações relevantes que servirão como âncora contribuindo assim para que se obtenha êxito ao que se espera. ALMEIDA (2017).

$\mathrm{O}$ processo de busca se refere a investigação dos fatores que poderão interferir no investimento, contudo no próximo item é fundamentado um breve relato sobre o processo de investigação pelo qual após estudos dos autores citados neste trabalho foi possível observar que, é fundamental nas tomadas de decisões.

Investigar o cenário e seu histórico antes da tomada de decisões, bem como trabalhar com possíveis falhas que podem ocorrer, é relevante ao tocante do objetivo pelo qual se espera suceder de forma evolutiva, pois o indivíduo é subjetivo o que varia sua situação emocional no momento, se resultará em agir de forma correta, ou irrelevante que, poderá ser prejudicado futuramente.

A análise de mercado, bem como a consulta a opiniões de terceiros experientes, pelos quais possuem determinada fonte de conhecimento, poderá contribuir para o alcance de objetivos, pois o ser humano pode ter o excesso de confiança que o deixará de visualizar possíveis riscos ao falhar nas tomadas de decisões. A busca por conhecimento é relevante ao tocante da investigação sobre o mercado atual pelo qual se tem interesse em investir.

O estudo sobre possíveis falhas e seu plano de ação, contribui de forma eficaz cuja função é prever as consequências já planejando de forma considerável pela qual será colocada em prática para suprir o dano ocorrido. Mesmo tomando a melhor decisão há risco de perdas, uma vez que, o mercado financeiro não é estável, há fatores externos que influenciam neste meio de forma positiva ou negativa.

O processo de investigação se torna relevante na contribuição de correr riscos menores em um investimento, a busca pelo investimento ideal se quer atentar ao comportamento e estado emocional para que estes não venham a interferir de forma ineficaz nas condutas realizadas.

\section{CONCLUSÃO}

As finanças comportamentais são de grande relevância para o mercado financeiro, pois o comportamento dos indivíduos baseia-se na situação pela qual está vivenciando no momento e que, para a tomada de decisão, é necessário analisar o cenário e a situação atual do mercado bem como evidenciar possíveis falhas que podem ocorrer e já atribuir um plano de ação, assim, indicar a atitude correta a ser executada já refletindo no resultado que se poderá obter, porém atentando-se que, mesmo tomando a melhor decisão, o resultado poderá não ser o melhor, uma vez que, a qualquer momento é possível correr riscos, mas há possibilidades pelas quais demonstram que os riscos podem ser menores. 
As Finanças Comportamentais é um assunto amplo, porém com poucas referências a serem pesquisadas nos tempos atuais, entretanto é relevante para se tornar um investidor qualificado. Conhecendo as emoções é possível trabalha-las a favor dos investimentos, uma vez que, o tempo no mercado financeiro é contínuo e requer cautela com suas escolhas que resultarão em curto ou em longo prazo.

Obtendo-se conhecimento das habilidades pelas quais são relevantes nas tomadas de decisões, os investidores mostram ser a peça chave que contribuirá na conquista do mercado financeiro.

Neste trabalho foi possível observar a busca de melhorias na tomada de decisão através do constante aprendizado e experiências cujo o fator relevante se baseia em investidores e terceiros que se atentam ao seu estado emocional baseado em seu comportamento, sendo este, resultado de suas atitudes, uma vez que, tomando a decisão adequada o indivíduo tem a probabilidade de vencer em seus investimentos o deixando satisfeito enquanto a perda de um investimento causa um desgaste maior em seu psicológico.

\section{REFERÊNCIAS}

ALMEIDA, Alexandre Antonio Antunes de. Modelo de comportamento de investidores como indutores de contágio no ambiente financeiro brasileiro - Universidade Católica de Brasília. Brasília. 2017.

BERGER, Bruno; PESSALI, Huáscar Fialho. A teoria da perspectiva e as mudanças de preferência no mainstream: um prospecto Lakatoseano. Brazilian Journal of Political Economy, v. 30, n. 2, p. 340-356, 2010.

CHIAVENATO, I. Introdução a teoria geral da administração: uma visão abrangente da moderna administração das organizações. Rio de Janeiro: Elieser, 2003.

DE MOURA SOUSA, Fábio. Gestão de Riscos. REVISTA da Secretaria de Economia e Finanças do Exército - SEF, v. 1, p. 8-18, 2018.

DONADIO, Rosa. O perfil de risco do investidor e a tomada de decisão: uma abordagem comportamental. Tese (doutorado) - Universidade de São Paulo. São Paulo, p. 185. 2018.

GARCIA-MARQUES, Leonel; FERREIRA, Mário AB. Daniel Kahneman: A economia mental e o Nobel da economia. Psicologia, v. 17, n. 2, p. 475-483, 2003.

GIL, Antonio Carlos. Como elaborar projetos de pesquisas. $4^{a}$ edição. São Paulo: Atlas, 2002.

GONSALVES, Elisa Pereira. Iniciação a pesquisa científica. $4^{a}$ Edição Revisada e Atualizada. Campinas, SP: Editora Alínea, 2007.

KAHNEMAN, Daniel. A hora de pedir conselhos. Sumários Revista da ESPM, n. 2, p. 50$55,2015$.

LIMA, Murillo Valverde. Um estudo sobre finanças comportamentais. RAE-eletrônica, v. 2, 
n. 1, p. 1-19, 2003.

MARTINS, Gilberto Andrade; THEÓPHILO, Carlos Renato. Metodologia da investigação científica para ciências sociais aplicadas. $2^{a}$ Edição. São Paulo: Atlas, 2009.

MILANEZ, Daniel Yabe. Finanças comportamentais no Brasil. Tese (doutorado) Universidade de São Paulo - São Paulo. 2003.

PEREIRA, Adriano José; MARIN, Solange. Lei da escassez e comportamento econômico: uma leitura institucional. Revista Econômica, v. 18, n. 2, 2017.

SANTOS, Marcos Rabelo; DACORSO, Antônio Luiz Rocha. Intuição e racionalidade: um estudo sobre a tomada de decisão estratégica em empresas de pequeno porte. Revista de Administração da Universidade Federal de Santa Maria, v. 9, n. 3, p. 448-463, 2016.

SBICCA, Adriana. Heurísticas no estudo das decisões econômicas: contribuições de Herbert Simon, Daniel Kahneman e Amos Tversky. Estudos Econômicos (São Paulo), v. 44, n. 3, p. 579-603, 2014.

TOMASELLI, Tatiana Renaux; OLTRAMARI, Leandro Castro. A psicologia do mercado acionário: representações sociais de investidores da BOVESPA sobre as oscilações dos preços. Estudos de psicologia, v. 12, n. 3, p. 275-283, 2007. 